$03,07,11$

\title{
Особенности структуры германия, обработанного в планетарной мельнице
}

\author{
(C) Т.А. Гордеева ${ }^{1,2}$, Д.А. Овсянников ${ }^{1}$, М.Ю. Попов ${ }^{1,2}$, Б.А. Кульницкий ${ }^{1,2}$, В.Д. Бланк ${ }^{1}$ \\ ${ }^{1}$ Технологический институт сверхтвердых и новых углеродных материалов, \\ Москва, Троицк, Россия \\ ${ }^{2}$ Московский физико-технический институт, \\ Долгопрудный, Московская обл., Россия \\ E-mail: gordeeva.ta@phystech.edu
}

Поступила в Редакцию 9 апреля 2020 г.

В окончательной редакции 9 апреля 2020 г.

Принята к публикации 24 апреля 2020 г.

Методами высокоразрешающей просвечивающей электронной микроскопии на приборе JEM-2010 исследовали структуру порошкового германия, обработанного в планетарной мельнице в присутствии небольших добавок (5-25\%) порошка алмаза. В результате обработки обнаружены двойники и дефекты упаковки в германии по плоскости $\{111\}$. Показано, что деформация германия приводит также к политипии. Обнаружена фаза $9 R$, в которой имеет место следующая последовательность слоев: . . ВАВСВСАСА... В некоторых частицах произошел частичный или полный фазовый переход GeI $\rightarrow$ GeIV и GeI $\rightarrow$ GeIII.

Ключевые слова: германий, двойникование, просвечивающая электронная микроскопия, пластическая деформация.

DOI: 10.21883/FTT.2020.10.49902.080

\section{1. Введение}

Методы высокоэнергетической обработки материалов имеют давнюю историю [1]. В настоящее время они активно используются для получения нанокристаллов. К процессам, происходящим во время обработки исследуемого материала в планетарной мельнице, приковано внимание многих исследователей. Кроме самого измельчения, интерес представляют процессы, происходящие в частицах материала: дефектообразование и фазовые превращения. В связи с тем, что в наночастицах велика доля атомов в тонком поверхностном слое, эти процессы могут происходить в них иначе, чем в крупных частицах. Размерные и деформационные эффекты в измельченных частицах исследуют методами нейтронографического и рентгенографического анализа [2,3]. Известно, что после обработки материалов в планетарной мельнице часто наблюдается уширение рентгеновских линий. Это связано с уменьшением размеров частиц и с наличием в них микронапряжений. Авторам [4] удалось разделить размерную и деформационную составляющие.

Однако только в небольшом числе опубликованных работ приводятся данные просвечивающей электронной микроскопии, иллюстрирующие возникновение дефектов и фаз высокого давления [5-8]. В настоящей работе была предпринята попытка методами электронной микроскопии исследовать особенности структуры частиц $\mathrm{Ge}$ после обработки в планетарной мельнице. Германий - широко используемый материал в электронике, металлургии, его добавляют в керамику, в термоэлектрики и т.д. Известно, что наличие дефектов в германии приводит к смещению уровня Ферми, что в свою очередь приводит к увеличению концентрации свободных носителей заряда и росту проводимости [9] ввиду наличия неравновесных вакансий и межузельных атомов на границах зерен. Деформация германия влияет также на его оптические свойства. Планетарную мельницу можно считать своеобразной сдвиговой камерой высокого давления, где материал может подвергаться циклическим нагружениям до $6 \mathrm{GPa}[10]$ и большим пластическим деформациям, что приводит к реализации фазовые превращения $[7,8]$.

Как известно, при нормальных условиях $\mathrm{Ge}$ имеет кубическую структуру решетки алмаза с параметром $a=0.5657 \mathrm{~nm}$. Фаза GeIV имеет структуру гексагонального алмаза и параметры $a=0.394 \mathrm{~nm}$ и $c=0.655 \mathrm{~nm}$.

Банди и Каспер [11] исследовали германий при комнатной температуре и первыми получили плотную модификацию германия GeIII сжатием обычного кубического германия до $12 \mathrm{GPa}$. Фаза высокого давления GeIII, называемая также фазой Каспера, характеризуется тетрагональной решеткой с параметрами $a=0.593 \mathrm{~nm}$ и $c=0.698 \mathrm{~nm}$.

\section{2. Эксперимент}

В работе использовали планетарную мельницу Fritsch Planetary Micro Mill PULVERISETTE 7 premium line со стальным барабаном и стальными шарами. Порошки алмаза и германия были смешаны в соотношении $1: 4$ по массе. Длительность обработки составляла $10 \mathrm{~h}$, цикл обработки состоял из $1 \mathrm{~min}$ измельчения и $3 \mathrm{~min}$ 
$a$

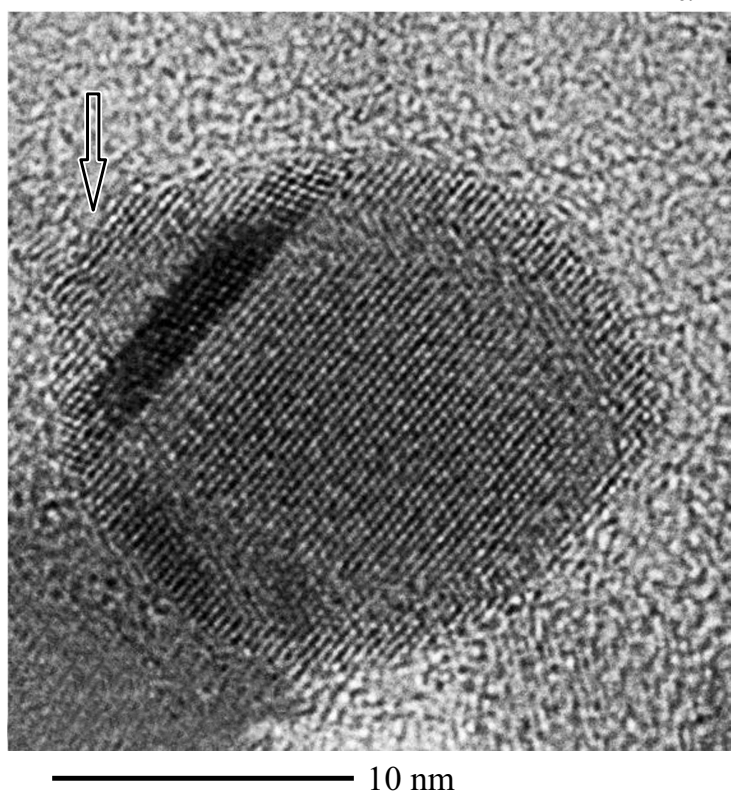

$b$

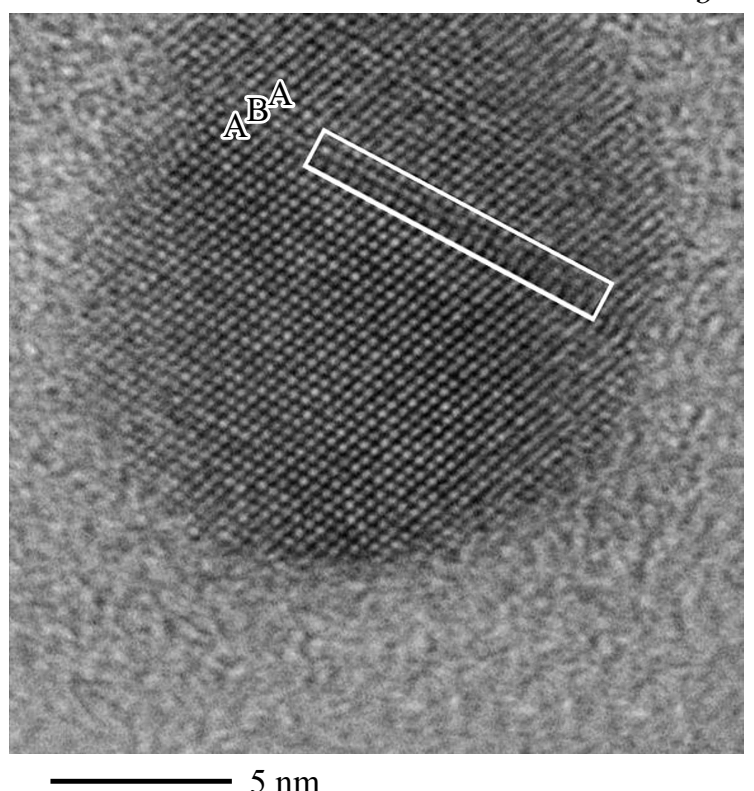

Рис. 1. Частицы Ge после обработки в мельнице: $a$ ) поверхностные слои частицы Ge (показаны стрелкой), искаженные в результате деформации; $b$ ) дефект упаковки в $\mathrm{Ge}$, содержащий упаковку слоев $\mathrm{ABA}$.

охлаждения. В [12,13] было показано, что максимальная температура образца при используемом цикле обработки в планетарной мельнице не превышает $420 \mathrm{~K}$. После обработки порошок исследовали методом просвечивающей электронной микроскопии (ПЭМ). Для ПЭМ-исследований использовали электронный микроскоп JEOL JEM-2010 TEM с применением энергодисперсионной рентгеновской спектроскопии (EDS).

\section{3. Результаты и обсуждение}

Наши наблюдения показали, что обработка порошков в течение 5 и $20 \mathrm{~min}$ приводила только к частичной фрагментации частиц, тогда как после двухчасовой обработки появлялись многочисленные дефекты. В результате в приповерхностном слое возникают сильные искажения кристаллической решетки (рис. $1, a$ ). Это соответствует представлению о том, что процессы деформации и разрушения часто начинаются в тонком приповерхностном слое. Исследование структурных дефектов в GeI после обработки в мельнице показало, что часто в частицах присутствуют двойники по традиционной для структуры алмаза плоскости $\{111\}[14]$.

На рис. $1, b$ показан дефект упаковки в частице GeI. Этот дефект содержит упаковку слоев АВА, показанную в прямоугольнике. Такую конструкцию можно рассматривать как двойниковую границу, которую принято обозначать как $\Sigma=3$ [15]. В то же время упаковка ABA представляет собой фрагмент гексагональной решетки SiIV. Другими словами, образование дефекта упаковки приводит к возникновению фрагмента GeIV в GeI. Как правило, такая двойниковая граница является когерентной. Часто встречаются частицы, в которых реализуется двойникование по нескольким плоскостям $\{111\}$. На рис. 2, a показано как две границы первого порядка образуют границу $\Sigma=9$. На рис. $2, b$ показана частица со структурой GeIV, которая других фаз не содержит. Частица целиком перешла из GeI в GeIV. Таким образом, GeIV обнаружен как в виде полосок с упаковкой слоев ABA, которая возникла в результате образования дефектов упаковки в GeI, так и в виде отдельных частиц.

На рис. 3, $a$ показаны две частицы Ge c разными кристаллическими решетками, соответствующие фазам GeIII и GeI. На вставке показано FFT-изображение от левой частицы с кристаллической решеткой, соответствующей фазе Каспера GeIII. Эта фаза образуется в германии при обработке его давлением [16-18]. На рис. $3, b$ показан фрагмент частицы Ge c упаковкой слоев САВАВСВСАСАВА, что соответствует ромбоэдрической структуре $9 R$ или политипу GeIV с утроенным параметром с. Такая решетка может быть представлена в координатах гексагональной решетки с параметрами $a=0.394 \mathrm{~nm}$ и $c=1.965 \mathrm{~nm} .9 R$-структура встречается не впервые в решетке типа алмаза. Так, в [19] подобная структура была обнаружена в алмазе, выращенном на кремниевой подложке.

Особенности структуры материала, обработанного в планетарной мельнице, зависят от условий обработки: атмосферы, веса шаров, материала, из которого сделаны шары и камера, особенностей движения шаров, температуры и т.д. Известно, что температура шаров при обработке в планетарной мельнице в условиях нашего эксперимента не превышает $420 \mathrm{~K}[12,13]$. В [10] 

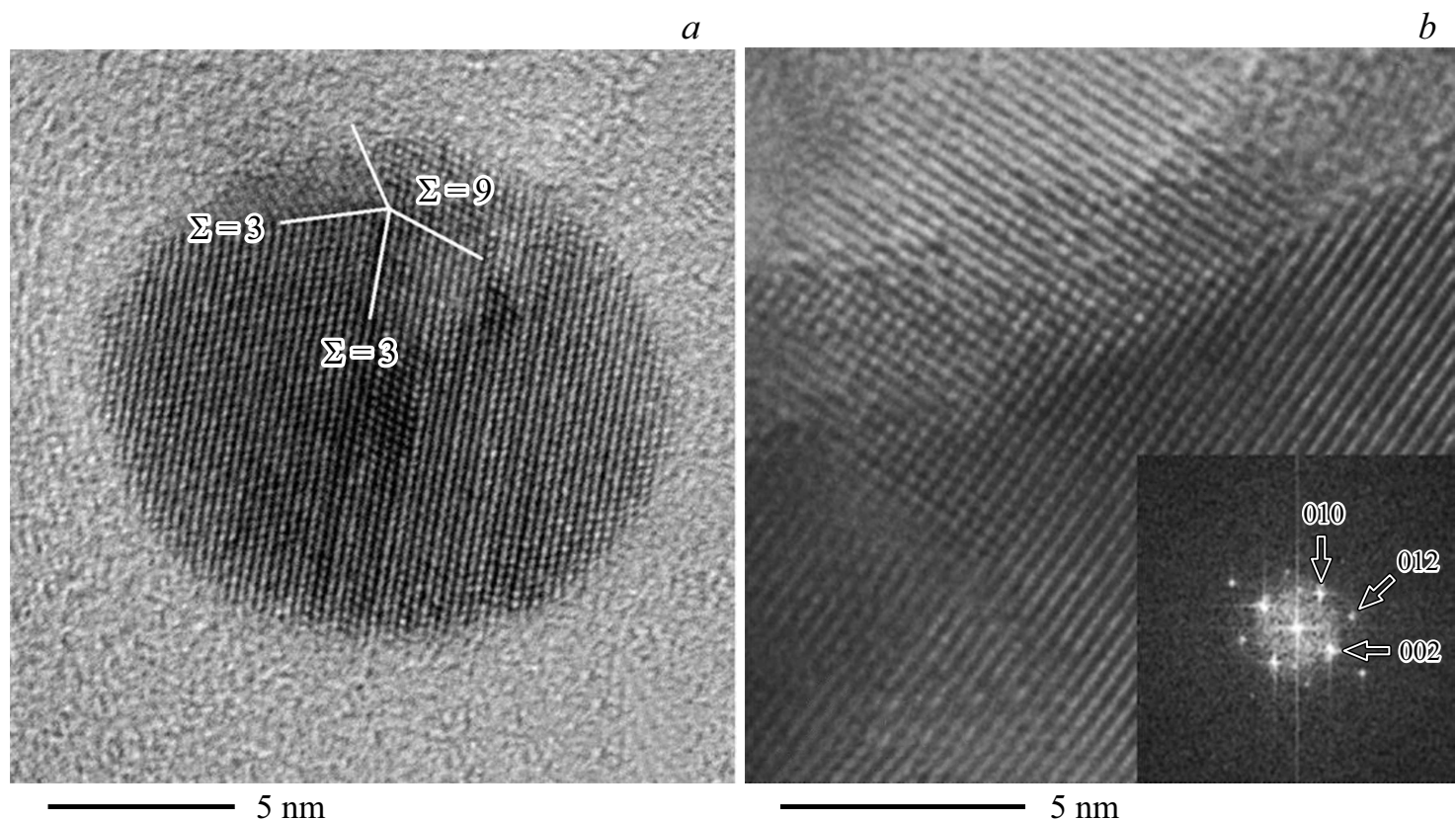

Pис. 2. $а$ ) Двойникование в GeI. Граница двойникования $\Sigma=9$ при пересечении двух границ $\Sigma=3 ; b)$ Фрагмент GeIV и соответствующее изображение дифракционных рефлексов, полученное с помощью Фурье-преобразования.

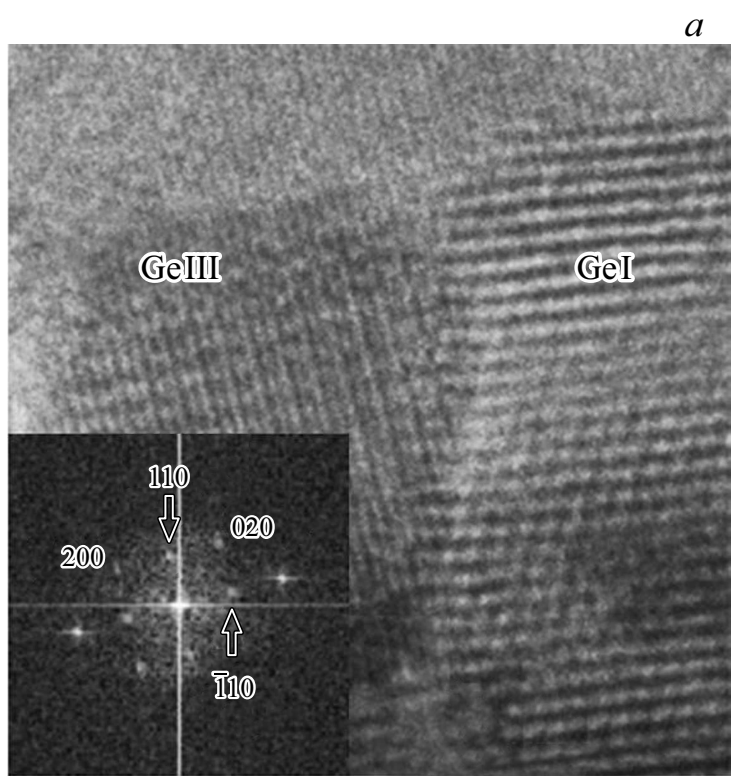

$5 \mathrm{~nm}$

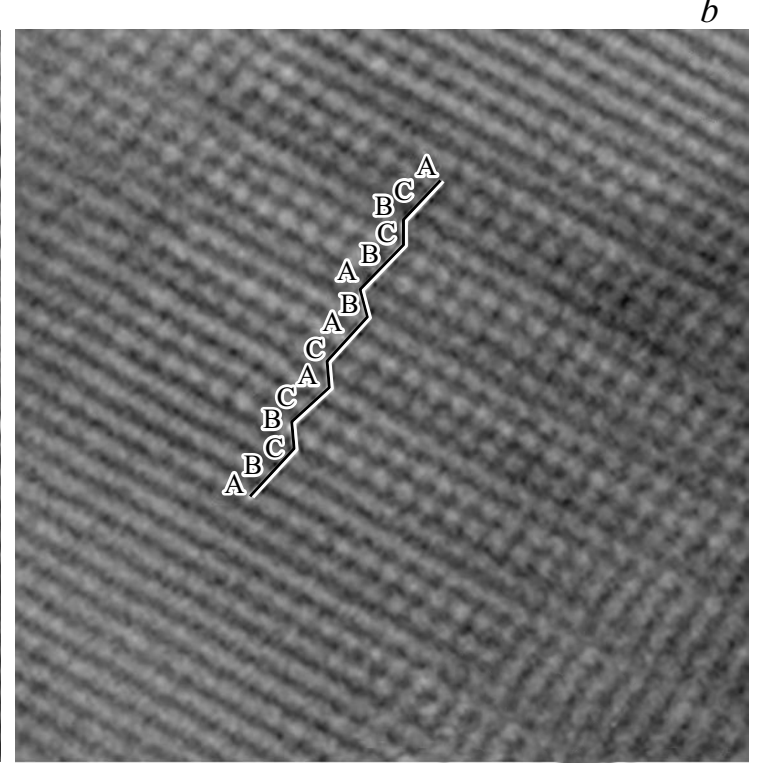

$5 \mathrm{~nm}$

Рис. 3. a) Две частицы Ge с разными кристаллическими решетками, соответствующие фазам GeIII и GeI. На вставке показано изображение дифракционных рефлексов, полученное с помощью Фурье-преобразования от левой частицы $(\mathrm{GeIII}) ; b)$ политип Ge с упаковкой ВСВСАСАВА, что соответствует $9 R$-структуре.

было показано, что в процессе обработки в мельнице частицы в порошке могут подвергаться давлению до $6 \mathrm{GPa}$. При этом они деформируются и разрушаются. Каждая частица может быть подвержена ударам шаров многократно; при этом в промежутке между ударами она успевает остыть. Количество таких ударов зависит от времени обработки. Длительность удара оценивается в $10^{-5}$ с [10]. По-видимому, многочисленные соударения внутри мельницы позволяют рассматривать процессы в мельнице, как одновременное воздействие температуры, давления и сдвига.

Снижение давления перехода при сдвиге позволяет получать фазы высокого давления в планетарной мельнице при значительно более низких давлениях, чем в условиях гидростатических давлений. Как следует из [17], давление появления фаз $\mathrm{Ge}(\mathrm{Si}) \mathrm{III}$ с увеличением 
угла сдвига составляет для германия $3.1 \pm 0.3 \mathrm{GPa}$ и для кремния $2.5 \pm 0.2 \mathrm{GPa}$. Другими словами, превращение в кремнии реализуется при меньших давлениях, чем в германии. Этим можно объяснить малое количество фазы Каспера в исследованном Ge по сравнению с результатами [8], где при обработке порошка кремния в аналогичных условиях удалось обнаружить много частиц, содержащих фазу SiIII.

\section{4. Заключение}

В результате обработки порошка германия в планетарной мельнице обнаружены двойники и дефекты упаковки по плоскости $\{111\}$. Показано, что деформация германия приводит также к политипии. Обнаружена ромбоэдрическая фаза $9 R$, в которой имеет место следующая упаковка слоев: . . ВАВСВСАСА . . . В некоторых частицах обнаружены фазы высокого давления GeIII и GeIV.

\section{Благодарности}

Настоящая работа выполнена с использованием оборудования ЦКП в ФГБНУ ТИСНУМ (электронный микроскоп JEOL JEM 2010, планетарная мельница Planetary Micro Mill PULVERISETTE 7 Premium Line).

\section{Конфликт интересов}

Авторы заявляют, что у них нет конфликта интересов.

\section{Список литературы}

[1] P. Baláž. Mechanochemistry in Nanoscience and Minerals Engineering. Berlin-Heidelberg, Springer, 413 (2008).

[2] А.С. Курлов, И.А. Бобриков, А.М. Балагуров, А.И. Гусев. Письма в ЖЭТФ 100, 712 (2014)

[3] A.I. Gusev, A.S. Kurlov. Nanotechnology 19, 26, 265302 (2008).

[4] A.S. Kurlov, A.I. Gusev, E.Yu. Gerasimov, I.A. Bobrikov, A.M. Balagurov, A.A. Rempe. Superlat. Microstruct. 90, 148 (2016).

[5] Jianhong He, Kyung H. Chung, Xiaozhou Liao, Yuntain T. Zhy, Enrique J. Lavernia. Met. Mater. Transact. A 34A, 707 (2003).

[6] J.Y. Huang, Y.K. Wu, H.Q. Ye. Acta Mater. 44, 1211 (1996).

[7] J.Y. Huang, Y.K. Wu, H.Q. Ye. Appl. Phys. Lett. 66, 3 (1995).

[8] B. Kulnitskiy, M. Annenkov, I. Perezhogin, M. Popov, D. Ovsyannikov, V. Blank. Acta Cryst. B72, 733 (2016).

[9] Д.А. Овсянников, М.Ю. Попов, С.Г. Буга, В.В. Аксененков, А.Н. Кириченко, Р.Л. Ломакин, С.А. Тарелкин, Е.В. Татьянин, В.Д. Бланк. Тр. МФТИ 4, 3 (2012). С. 36.

[10] D. Maurice, T.H. Cortney. Met. Mater. Trans. A 21, 289 (1990).

[11] F.P. Bundy, J.S. Kasper. Science 139, 3552, 340 (1963).

[12] T. Gordeeva, B. Kulnitskiy, D. Ovsyannikov, M. Popov, V. Blank. Chem. Phys. Lett. 730, 138 (2019).

[13] Y.S. Kwon, K.B. Gerasimov, S.K. Yoona. J. Alloys Comp. 346, 276 (2002).
[14] B. Kulnitskiy, I. Perezhogin, G. Dubitsky, V. Blank. Acta Crystallographica B 69, 474 (2013).

[15] D. Shechtman, A. Feldman, J. Hutchinson. Mater. Lett. 17, 211 (1993).

[16] V.D. Blank, В.A. Kulnitskiy. High Press. Res. 15, 31 (1996).

[17] В.Д. Бланк, Э.И. Эстрин. Фазовые превращения в твердых телах при высоком давлении. Физматлит, М. (2011).412 с.

[18] Е.Ю. Тонков. Фазовые диаграммы элементов при высоком давлении. Наука, М. (1979). 192 с.

[19] Y. Lifshitz, X.F. Duan, N. Shang, Q. Li, L. Wan, I. Bello, T. Lee. Nature 4112, 404 (2001).

Редактор К.В. Емцев 